\title{
Research on Staff Flow Risk Management in IT Industry
}

\author{
Tang Ziyang, Wei Xuefang, Wang Zhiqiang \\ Wuhan University of technology, HuBei, Wuhan, 430070 \\ hunter2011@foxmail.com
}

Keywords: IT Industry; Staff Flow, Risk Management

\begin{abstract}
As the current whole society substance tendency and the enterprise talent competition, the flow of talent has become a common phenomenon in society. Because of high requirements for innovation, short product life cycle, knowledge-intensive features, IT companies more rely on the talents than other types of enterprises. The impact of brain drain on IT companies is generally larger than other types of enterprises, reflecting the faster, more serious consequences. This paper analyzes the reasons for the brain drain of Chinese IT companies and makes control strategy for IT companies before and after the development of the brain drain risk in order to continuously improve human resource management level and strive to control the serious brain drain situation.
\end{abstract}

\section{Introduction}

With the rapid development of computer and network technology, dramatically increase the number of IT companies, it has become a pillar industry of the national economy. China is now the world's largest economy in less developed countries, after the implementation of the reform and opening up policy from the Third Plenary Session, China's national economy has maintained rapid, stable, rapid development momentum, the annual growth of GDP among the best in the world, so China in the world the economy has a very important impact. With further 开 put the international market and domestic market increase the degree of liberalization, foreign IT companies continue to enter the Chinese market, competition and resource sharing situation with domestic enterprises to form. IT enterprises due to the requirements of continuous innovation, product replacement fast, knowledge-based professionals highly concentrated, etc., depend on knowledge workers is higher than other types of enterprises. Therefore, the increasingly fierce competition among enterprises is mainly the competition for talent, companies leave no stone unturned to attract talent, however, an open market economy and other external environment and knowledge-intensive, high treatment, the age structure of the low and other professional staff itself Features also caused the industry personnel, especially knowledge workers greater mobility phenomenon, the brain drain has plagued many enterprises.

\section{The Definition of Brain Drain}

"Brain drain" is a special form of talent flow, originated in the 1950s and 1960s Britain, it is in a particular organization, technical expertise in specific areas and the talented people, leaving the original service object transferred to the new group organizations and regions. Within the international academic field, many Western researchers vivid the brain drain as "brain drain" is the word to describe the comparative image, but also shows that the loss is a gradual process of development, the essence of a think tank in the flow, and therefore the international community a typical representative of the brain drain. Based on business standpoint, the brain drain is updated employees, the adjustment process out some employees go, the brain drain is a special form of talent flow.

\section{Factors Affecting the Brain Drain}

Factors affecting the brain drain are: requirements of economic development, social and cultural factors, the development of science and technology, professional and effective update, the legal 
system of continuous improvement, adjustment of industrial structure, enterprise talent competition as well as on the structure of enterprises to adjust Wait. Brain drain consists mainly in two forms, one is from the enterprise out of business professionals involved in the flow of the social sphere, and the second is the internal talent in the post exchanges and responsibilities change, such as compensation, benefits, work is stable or corporate image training opportunities It can affect the brain drain. In the flow of talent among reasonable, positive flow is consistent flow of talent socio-economic development needs, otherwise a non-rational, reverse flow. Factors that affect a lot of brain drain, both among these factors also have intangible tangible. Tangible factors include salary, bonus and benefits, etc., intangible factors include the work of competent people for business sense of accomplishment and satisfaction. Brain drain affect mainly these two types of factors, sometimes a factor could cause the loss of talent, and sometimes the brain drain can lead to joint action on several factors

\section{The Control Strategy before IT Brain Drain Risk}

Improve the Recruitment Process. Job quality is directly related with the level of personnel turnover, so companies in the recruitment of talent should be inspected from the character, attitude and professional skills and competencies in four areas. Corporate recruiters should first consider the candidate's character and attitude, professional skills and abilities if the existence of a lack of candidates in some respects, then can be compensated by training business late, but there is a problem should the candidates character and mentality if then the business is difficult to change it and make it serve the effectiveness of the enterprise.

Improve the Talent Incentive System. Treatment of employees, the most important is the reward, and the reward includes extrinsic rewards and intrinsic rewards. Extrinsic rewards referring to the company to provide wages, bonuses, benefits, etc., and intrinsic rewards refers to a sense of competence, a sense of accomplishment and satisfaction of work, that is, management is often said that the physical needs and psychological needs. Extrinsic rewards is the foundation, the reason why people come out in business, in large part because in order to survive, to make their live better material life, but also to some extent, extrinsic rewards also reflects the value of talent. There are many ways to motivate, but the pay can be said to be one of the most important and easiest to use of the method. Because the number of external remuneration in a way reflects the value of talent, and the recognition of their work on behalf of the enterprise, and even in some companies also on behalf of the working ability and talent development prospects. Not satisfied to external remuneration is a major reason for the loss of corporate officers.

Enterprise incentive mechanism determines the competitiveness of enterprises talent sense. If the distinction between the words according to the way incentives, incentives and material incentives can be divided into two modules of non-material incentives. Enterprises can establish salary system for enterprise management personnel basic pay system, enterprise management personnel of the economic interests of the general staff copper interests separate, linked directly with business performance to achieve incentives for management talent. After the money belongs to the people of the underlying demand in the money available to meet their basic needs of life, people generally will have a higher level of need. Therefore, enterprises should get rid of before the traditional method (substance) as the only incentive, the top demand of talent that is hard on the spiritual needs. On the non-material incentives, companies can develop according to the specific circumstances of their own development objectives and measures of cultural integration, using a variety of methods to guide personnel correct cultural mentality, ideas, values and behavior.

Pay Attention to Career Planning. Currently, many candidates before the candidates would have planned his career and have clear career goals, but more and more people to apply for jobs, work content is consistent with their own planning and career goals are also increasingly the more seriously. Therefore, companies should also pay attention to the introduction of personnel training for personnel management and career planning. For this reason, companies should make the greatest possible to provide them with education, specialized training and the opportunity to learn, not unreasonably suppress their willingness to learn. Meanwhile, enterprises should always pay 
attention to career planning personnel, the timely detection of the needs of their career planning and timely manner to enhance its position, try to meet the expectations of their career goals and career development planning in order to maximize retain talent.

Strengthen the Building of Enterprise Culture. Corporate culture is a cultural phenomenon exists objectively and it is the most fundamental role is sublimation ideological level employees, the success of the corporate culture in a way for people subtle role and sometimes more effective than material incentives. The central role of corporate culture is to set up a common vision, to promote common values. Shape corporate culture like a concentric circle, it will energy is concentrated in the center of the enterprise, up to the top management down to junior staff, which in the form of radiation to the surrounding businesses to the various levels of distribution.

Improve the Business-Related Mechanisms. Enterprises must first establish a scientific cadre selection and appointment system, enterprises should pay attention and apply the theories and methods of cadre management and modern human resource management, the establishment of selection and appointment system specification to form full of vigor and vitality, it is conducive to the selection of talent to stand out personnel System. Enterprise development and talent personal when unbalanced development will inevitably lead to the loss of talent, therefore, enterprises should take precautions to prepare in advance, forming a reservoir of talent looking for candidates with the appropriate potential and its systematic training, with current job talent assistant as soon after the loss of its successor, in order to ensure the supply of jobs and the loss of defensive talent.

\section{The Control Strategy after the Brain Drain Risk}

Conduct Exit Interviews When the Staff Decided to Leave. When employees decided to leave, and their enterprises to conduct exit interviews, its main purpose is to understand the real cause of employee turnover interviews, so as to take measures to retain targeted. With particular attention to those from their own problems so that it can help enterprises improve their work targeted to maintain targeted personnel management and initiative.

Let Successor Talent Timely Posts. Because talent succession planning companies in order to avoid brain drain and build, so when the brain drain, companies can immediately call the appropriate personnel from among the succession plan to train personnel to replace the loss of talent vacancies. Enterprises can use strategic human resource management (SHRM) thinking, good planning of human resources, in terms of jobs for the key and you can use the connection plan, in peacetime positions to cultivate potential successors.

Strengthening Human Resource Management. Risk management for the loss of their core talent, companies can set up in-house expertise in crisis management, updating the concept of human resource risk management, and constantly improve and perfect the systems department, HR department changed good "blocking" and poor "sparse "the wrong idea.

Brain Drain Archives Management. After the brain drain, that does not mean the elimination of all enterprises and their contact, so companies can build employee turnover management files, and file content may include: loss of talent whereabouts, the loss of reason, contact information and other content, in particular the loss of reason and contact information should be detailed records, businesses and shall be updated with information about the loss of talent and keep its daily communication and contact.

\section{Conclusion}

In this paper, the causes of the current brain drain of IT companies were analyzed combined with the characteristics of current IT companies. In the perspective of improving the level of human resource management, we explore the countermeasures of establishment of IT companies brain drain phenomenon in line with China's national conditions and try to improve employee satisfaction, so that our IT companies, especially SMEs can better attract talent, retain talent, and make rational use of scientific talent, and gradually reduce the current high personnel turnover, so that the enterprise flow of talent keep a status of virtuous cycle. 


\section{References}

[1] G. Li. Knowledge about the Brain Drain and Ecological Knowledge Model. Science and Technology Progress and Policy, 2008 (04).

[2] X. Yang. Sustainable Development of Human Resources and Corporate Training Development. Human Resources Hair, 2005 (04): 66-67.

[3] Y.Yang. SMEs How to Conduct Training. Human Resources Development, 2004 (Z1).

[4] M.Zhang. Influence Factors of IT Corporate Employees Turnover. China Soft Science, 2003 (05).

[5] S.M.Li, Research on Factors Determines Employee Job Satisfaction. Statistical Research, 2001 (08). 